Journal of Engineering and Applied Sciences 15 (2): 596-601, 2020

ISSN: 1816-949X

(C) Medwell Journals, 2020

\title{
Teeth Cleaning Practices of Infants Attending Paediatric Out-Patient Department at Tembisa Hospital: Counting Carrying of Caries
}

\author{
${ }^{1}$ Modjadji Mary Masetla and ${ }^{2}$ Solly Matshonisa Seeletse \\ ${ }^{1}$ Department of Community Dentistry, \\ ${ }^{2}$ Department of Statistics and Operations Research, \\ Sefako Makgatho Health Sciences University, Molotlegi Street, Ga-Rankuwa, South Africa
}

\begin{abstract}
The study investigated primary teeth caries in infants younger than 6 years old who attended paediatric out-patients department at Tembisa hospital. The study compares prevalence of caries between breast and bottle-fed participants. A bivariate categorical data analysis quantitative study design was used. The study population consisted of children younger than 6 years who were treated at the hospital for teeth caries from 1st November to 3rd December 2010. Every child whose parent gave consent for their children was included in the study sample. A total of 245 parents consented. The data collection tool was a modified WHO oral health assessment form. Data was collected and captured in a spread sheet. Stata was used for analysis. Analyses were done mostly by presenting descriptive statistics. Bottle-fed children were more likely to develop caries than breast-fed ones. Breast-fed children showed to have a lower risk of developing caries than bottle-fed ones. Some parents did not adhere to teeth cleaning instructions for the children as some teeth were not cleaned regularly. Teeth caries were more prevalent in children whose teeth were not cleaned regularly.
\end{abstract}

Key words: Caries, dentofacial, early childhood caries, population, adhere, developing

\section{INTRODUCTION}

Dental caries, also known as cavities, as elucidated by Silk (2014) is a breakdown of teeth as a result of acids that the bacteria produce as they soften hard tissues [cementum, dentin and enamel]. The bacteria create the acid by breaking down food debris and sugar on the surface of the teeth. Sugar in food serves as the main source of energy for the bacteria. Hence and as Schwendicke et al. (2015) attest, diet that is high in sugar is a caries risk factor. Caries are formed when the breakdown of minerals exceeds their accumulation from cradles [such as saliva] as Venturi and Venturi (2009) informs. This point therefore, also insinuate that the conditions that lead to less saliva such as diabetes mellitus and Sjogren's syndrome are risk factors for caries. There are also some medications [e.g., antihistamines and antidepressants] that decrease the production of Saliva. According to several researchers, De Oliveira et al. (2017) and Mast et al. (2013), more other factors that cause caries are gums that regress to cause exposure of tooth roots, improper mouth cleaning [or even not cleaning it] and poverty.

Laudenbach and Simon (2014) explain that caries may show in several different colours that will be visible on the teeth, from yellow to black. Effects of caries could include pain on the teeth or gums and difficulty with eating. According to Otsu et al. (2014), there may be complications resulting from caries which may include abscess formation, infection, loss of tooth and tissue inflammation around the tooth.

Even though they occur for everyone, hygienic issues about tooth caries are not well known in remote communities (Vos et al., 2012). Hence, the illumination that caries is another name for tooth decay can make many people aware that they should make caries a serious concern. Despite it being totally preventable, the caries disease has become easy to acquire, rife and persistent at present (Mast et al., 2013). It is, however, a consolation that caries is fully avoidable.

Caries can be painful and at that point the pain should be treated as it is unbearable. The pain should be reduced or eliminated using medication. Common medicines used for managing the pain from dental caries is paracetamol, also known as acetaminophen or ibuprofen (Hafez et al., 2012; Silk, 2014; Silva et al., 2016). The painkillers used for pain are neither used to prevent dental caries nor to cure them.

Preventing caries: As is known what causes dental caries, Hiremath (2011) insinuates that dental cariescan be prevented by regularly cleaning of the teeth, following a diet that is low in sugar and consuming small amounts of fluoride. Teeth should be brushed two times a day is one way of reducing the chance to get caries and even to prevent it. The brushing should be appended with flossing

Corresponding Author: Solly Matshonisa Seeletse Department of Statistics and Operations Research, Sefako Makgatho Health Sciences University, Molotlegi Street, Ga-Rankuwa, South Africa 
between the teeth daily is suggested (Ferraz et al., 2012). It is also said (Listl et al., 2015) that the treating of the dental caries of a mother may decrease the dental caries risk in her children. When the caries are few in a mother, it decreases the amounts of some bacteria that she may distribute to the children. Another way to reduce the risk is to do screening as it can lead to early detection. Twetman (2015) explains that prevention is possible, especially with correct methods as well as early detection.

Curing already affected teeth: When dental caries are still at the early stages, there is a possibility of treating and curing, according to Twetman and Dhar (2015). According to Borzabadi-Farahani et al. (2011), it depends on the degree of tooth destruction by caries. When the tooth damage is at its early stages, several treatments can be applied to repair the tooth to proper function. In the case of a fully damaged tooth through caries, the affected tooth/teeth may be removed. Otsu et al. (2014) explain that there is currently no known method to resuscitate teeth that are already dead. The relationship between sugars and dental caries is important as Sheiham and James (2014) inform that treatment accessibility is often poor in the developing world.

Some statistics on dental caries: The Global Burden of Disease study explains that at the global level, close to $35 \%$ of the world population have dental caries in their permanent teeth that almost every adult has dental caries sometime in life and that dental caries affects close to 650 children. Also, dental caries are reported (Hujoel et al., 2018; Kraivaphan et al., 2013) to have become more common in both children and adults in recent years. The disease is much more prevalent in the developed economies because of larger consumption of simple sugar and less prevalent among the developing economies (Listl et al., 2015).

Background to the study: Dental caries is a common disease in children (Cunnion et al., 2010; Milgrom et al., 2009) where it is known as Early Childhood Caries (ECC). As discussed earlier, dental caries is a common but preventable disease which occurs and can be uncomfortable because of the severe pain it causes. Its pain can be reduced or eliminated but not implying that the diseases is cured. ECC affects primary upper anterior teeth, upper and lower primary first molars and the lower primary canines (Tellez et al., 2013). Petti (2010) characterise ECC as the presence of decayed, missing or filled dental surfaces in a primary tooth affecting children up to 5 years old. Bagramian et al. (2009) explain that global epidemiological data show a marked increase in the prevalence of dental caries worldwide. The global increase in dental caries prevalence affects children and adults; deciduous and permanent teeth, coronal and root surfaces. A study was conducted on primary teeth caries in children below 6 years of age attending paediatric out-patient department at the Tembisa hospital to determine their teeth-cleaning practices in order to determine the extent to which the ECC problem is being addressed.

Research context: The study took place in Tembisa hospital in the Tembisa township located in a semi-urban area in the Gauteng Province of South Africa. This hospital's Paediatric out Patient Department (POPD) accepts children patients who have been referred from peripheral clinics around Tembisa. The Tembisa Hospital Dental Clinic (THDC) treats patients who visit the hospital due to dental problems in the hospital.

\section{MATERIALS AND METHODS}

Study design: A quantitative descriptive methodology was used in this study. According to Creswell (2014), the quantitative research design is the standard experimental method of most scientific disciplines. This type of design uses traditional mathematical and statistical means to measure results conclusively. Krishnaswamy et al., (2006) define descriptive research as a fact-finding with adequate interpretations where fact finding would involve just data gathering. Therefore, a descriptive design was selected as the research question is more descriptive in nature. A descriptive study establishes only associations between variables (Creswell, 2014). The idea behind this type of research is to study frequencies, averages and other statistical calculations (Wegner, 2007).

Population: The study population consisted of an unlimited number of children patients visiting the POPD in Tembisa Hospital. The sampling frame consisted of those children who visited the hospital during the day. The estimated population size of children who visit the POPD in 1 month is about 315 [informed by a matron].

Sampling: The sample consisted of 245 children who attended POPD from the 1st November 2010 to 3rd December 2010. The parents/caregivers of the children were the targeted participants agreed to participate in the study by signing the consent form. Of these, 128 (48.67\%) were boys and 135 (51.33\%) were girls. For data collection, parent/guardians were given an oral health talk on the importance of keeping their children's teeth clean and free of caries how to clean the children's teeth and when to bring the children for regular dental check-ups. Sterilised dental mirrors and dental probes were used to visually examine selected children for dental caries.

Data collection and tool used: A decayed, missing and filled teeth (dmft) index was computed to obtain caries 
prevalence. The data collection instrument used in this study was a modified WHO oral health assessment form, 1997 (WHO, 1997, 2009; Santos et al., 2013). The parents had to inform whether the children under their care who had visited the POPD were brushing their teeth how they were brushing them and the frequencies with which they brushed their teeth. Excluded participants were those whose caregivers did not sign consent form and those whose parents refused to complete the form. This tool enables caries assessment in dentitions through the $\mathrm{dmft}$ index. A quantitative descriptive methodology was appropriate for this study. The study population consisted of younger than 6 years old children.

Data analysis: Analysis of data in this study entailed calculating percentages of whether the patients undertook the task mentioned. Percentages of certain categories were used in the study. Tables were used to present frequencies of the categories. Chi-squared tests of independence were used in the study. SPSS is the Statistical Package used in the study.

\section{RESULTS AND DISCUSSION}

Of the 263 modified WHO oral health assessment forms distributed, 245 (93.16\%) were useful and thus analysed. Three age categories were formed: children from 0-2; 2.1-4 and 4.1-6 years.

Teeth cleaning habits of participants: From Table 1, a total of 245 subjects were examined. Of these, 197 (80.41\%) were cleaning their teeth and 48 (19.59\%) were not.

Relationship between teeth cleaning and caries development: Of the 197 participants who cleaned their teeth, 94 (47.72\%) were free of caries and 103 (52.28\%) had caries. Of 48 who did not clean their teeth, 31 (64.18\%) were free of caries and 17 (35.42\%) had caries (Table 2).

Upon hypothesising that caries develop due to failure to clean the teeth, the chi-square test (Wackerly et al., 2008) was used. The hypothesis was that "teeth cleaning and caries development are independent". Let $\mathrm{o}_{\mathrm{i}}$ denote the ith observed frequencies and $\mathrm{e}_{\mathrm{i}}$ the corresponding expected frequencies in a contingency Table 3. The calculated chi-square value is:

$$
\chi^{2}=\sum_{i=1}^{k} \frac{\left(o_{i}-e_{i}\right)^{2}}{e_{i}}=4.3806
$$

The degree of freedom $(\mathrm{df})=$ (rows- 1 ) $($ columns-1) $=(2-1)(2-1)=1$. Thus, the critical value obtained from the table is $\chi_{1}^{2}$ (Nikoletseas, 2014). The test statistic does not exceed the critical value. Hence, the null
Table 1: Pattern of cleaning participant's teeth (atc)

\begin{tabular}{lcc}
\hline Teeth are cleaned & Frequency & Percentage \\
\hline Yes & 197 & 80.41 \\
No & 48 & 19.59 \\
Total & 245 & 100.00 \\
\hline
\end{tabular}

Table 2: Relationship between teeth cleaning and caries \begin{tabular}{llll}
\hline Atc & Caries absent (\%) & Caries present (\%) & Total (\%) \\
\hline
\end{tabular}

\begin{tabular}{llll}
\hline yes & $94(47.72)$ & $103(52.28)$ & $197(100)$
\end{tabular}

$\begin{array}{lrrr}\text { no } & 31(64.58) & 17(35.42) & 48(100)\end{array}$

\begin{tabular}{lrrr} 
Total & $125(51.02)$ & $120(48 / 98)$ & $245(100)$ \\
\hline
\end{tabular}

Table 3: Relationship between not cleaning teeth and caries

\begin{tabular}{lrc}
\hline $\mathrm{O}_{\mathrm{i}}{ }^{\prime}$ & Caries & No caries \\
\hline Yes & 94 & 103 \\
No & 31 & 17 \\
' $\mathrm{e}_{\mathrm{i}}$ ' & & \\
Yes & 100.5 & 96.5 \\
No & 24.5 & 23.5 \\
\hline
\end{tabular}

Table 4: Odds of developing caries and teeth cleanin

\begin{tabular}{lll}
\hline $\begin{array}{l}\text { Teeth were } \\
\text { cleaned }\end{array}$ & $\begin{array}{l}\text { Odds ratios } \\
\text { (95\% confidence interval) }\end{array}$ & p-value \\
\hline Yes & 1 & - \\
No & $0.97(0.44 ; 2.15)$ & 0.947 \\
\hline
\end{tabular}

Table 5: What is used to clean the participant's teeth?

\begin{tabular}{lcc}
\hline Tool used & Frequency & Percentage \\
\hline Toothbrush & 167 & 84.77 \\
Cloth & 30 & 15.23 \\
Total (n) & 197 & 100.00 \\
\hline
\end{tabular}

Table 6: Relationship between teeth cleaning and caries

\begin{tabular}{lcc}
\hline 'o' & Caries & No caries \\
\hline T'brush & 82 & 85 \\
Cloth & 16 & 14 \\
'e’ & & \\
T'brush & 83.1 & 83.9 \\
Cloth & 14.9 & 15.1 \\
\hline
\end{tabular}

hypothesis cannot be rejected. In particular, cleaning children's teeth did not indicate to be preventing ECC (Table 4).

Odds of developing caries and teeth cleaning: The odds of developing caries among participants who cleaned their teeth and the rest gave odds ratios were 1 and 0.97 with a p-value of 0.947 for those who did not clean their teeth (Table 5).

What is used to clean the participant's teeth?: Among the participants who were cleaning their teeth, 167 (84.77\%) used toothbrush and 30 (15.23\%) used a cloth. Among those who used toothbrush, 85 (50.9\%) were free of caries and $82(49.1 \%)$ had caries. Among those participants who used cloth, 14 (46.7\%) were free of caries and $16(53.3 \%)$ had caries.

The chi-square test was used on the hypothesis that "Teeth cleaning device and caries development are independent of each other”. Then (Table 6). The 
J. Eng. Applied Sci., 15 (2): 596-601, 2020

Table 7: Who cleans the participant's teeth?

\begin{tabular}{lcc}
\hline Cleaner of participant's teeth & Frequency & Percentage \\
\hline Parent/caregiver & 104 & 52.79 \\
Participants & 93 & 47.21 \\
Total & 197 & 100.00 \\
\hline
\end{tabular}

Table 8: Relationship between teeth cleaning tool and caries

\begin{tabular}{lcc}
\hline 'o' & Caries & No caries \\
\hline P/C & 48 & 56 \\
Partic & 47 & 46 \\
'e’ & & \\
T'brush & 50.2 & 53.8 \\
Cloth & 44.8 & 48.2 \\
\hline
\end{tabular}

Table 9: Teeth cleaning frequencies

\begin{tabular}{lcc}
\hline Occurrence & Frequency & Percentage \\
\hline Once a day & 135 & 68.53 \\
Twice a day & 39 & 19.80 \\
Other & 23 & 11.86 \\
Total & 197 & 100 \\
\hline
\end{tabular}

chi-square statistic $\chi^{2}=\sum_{\mathrm{i}=1}^{\mathrm{k}} \frac{\left(\mathrm{o}_{\mathrm{i}}-\mathrm{e}_{\mathrm{i}}\right)^{2}}{\mathrm{e}_{\mathrm{i}}}=7.8867$ exceeds the critical value $\chi_{1}^{2}=5.9915$ and the null hypothesis is rejected. Thus, using brush or cloth teeth affected caries existence (Table 7).

Who cleans the participant's teeth?: One hundred and four (52.79\%) participant's teeth were cleaned by their parents/caregivers while 93 (47.21\%) participants cleaned their own teeth. Among those whose parents/caregivers assisted, 56 (50.9\%) were free of caries and 48 (49.1\%) had caries. Among those who brushed their own teeth, 46 (49.5\%) were free of caries and 47 (50.5\%) had caries.

The chi-square test of independence was used to test the hypothesis "Teeth cleaner and caries development are independent of each other" (Table 8). The chi-square statistic is calculated as:

$$
\chi^{2}=\sum_{k=1}^{k} \frac{\left(o_{i}-e_{i}\right)^{2}}{e_{i}}=0.3948
$$

The critical value obtained from the table of chisquare values is $\chi_{1}^{2}=5.9915$. The test statistic does not exceed the critical value. Hence, the null hypothesis cannot be rejected. Thus, whoever cleans the children's teeth between the parent/caregiver and the children influences the ECC existence. It was also established that there was no supervision on those who cleaned their teeth (Table 9).

Teeth cleaning frequency: Table 8 shows that 135 (68.53\%) cleaned their teeth once a day, 39 (19.80\%) cleaned theirs twice a day and 23 (11.68\%) were inconsistent in cleaning their teeth (Table 10).

Relationship between the frequency of cleaning teeth and caries development: The table shows that among
Table 10: Relationship between the frequency of cleaning teeth and caries development

\begin{tabular}{lccr}
\hline $\begin{array}{l}\text { Freq of cleaning } \\
\text { teeth }\end{array}$ & $\begin{array}{c}\text { Caries } \\
\text { absent (\%) }\end{array}$ & $\begin{array}{c}\text { Caries } \\
\text { present (\%) }\end{array}$ & \multicolumn{1}{c}{$\begin{array}{c}\text { Total } \\
(\%)\end{array}$} \\
\hline Once a day & $66(48.89)$ & $69(51.11)$ & $135(100)$ \\
Twice a day & $20(51.28)$ & $19(48.72)$ & $39(100)$ \\
Other & $8(34.78)$ & $15(62.55)$ & $23(100)$ \\
Total & $94(47.72)$ & $103(52.28)$ & $197(100)$ \\
\hline
\end{tabular}

Table 11: Relationship between extent of teeth cleaning and caries

\begin{tabular}{lcc}
\hline 'o’ & Caries & No caries \\
\hline Once & 66 & 69 \\
Twice & 20 & 19 \\
Other & 8 & 15 \\
'e’ & & \\
Once & 64.4 & 70.6 \\
Twice & 18.6 & 20.4 \\
Other & 11.0 & 12.0 \\
\hline
\end{tabular}

those whose teeth were cleaned once a day, 66 (48.89\%) were free of caries while $69(51.11 \%)$ had caries. Among those whose teeth were cleaned twice a day, 20 (51.28\%) were free of caries and 19 (48.72\%) had caries. Among those whose teeth cleaning frequency was not consistent, 8 (34.78\%) were free of caries and 15 (62.55\%) had caries.

The chi-square tested "Teeth cleaning frequencies and caries development are independent of each other" (Table 11). The chi-square statistic is:

$$
\chi^{2}=\sum_{i=1}^{k} \frac{\left(o_{i}-e_{i}\right)^{2}}{e_{i}}=1.8456
$$

The $\mathrm{df}=1$, the critical value $\chi_{1}^{2}=5.991$ and the test statistic is less than the critical value. Hence, the null hypothesis is not rejected. Thus, repeated cleaning of teeth reduces ECC.

Some children's teeth were not cleaned. Caries were found in both groups. The odds for developing caries were almost equal. Cleaning was done with either a cloth or toothbrush. Also, caries development did not exist more for any group. The children were either assisted by guardian to clean their teeth or cleaned their own teeth. The proportions of having ECCs for the two groups were close. The chi-square test did not indicate influence in any method to be causing caries. No supervision for children who cleaned their teeth. Also, cleaning the teeth more reduced ECC.

\section{CONCLUSION}

The study expresses that caries were found to be more prevalent for cases where teeth were cleaned less while the cases where teeth were not cleaned regularly produced much more caries. It is therefore, established that cleaning the teeth more reduced ECC in children. It is also resolved that children who were not assisted in cleaning their teeth were also not supervised to do it right. 


\section{ACKNOWLEDGEMENT}

The researchers acknowledge the support of the two departmentsin which they research, for encouraging hard work on the project.

\section{REFERENCES}

Bagramian, R.A., F. Garcia-Godoy and A.R. Volpe, 2009. The global increase in dental caries: A pending public health. Am. J. Dent., 22: 3-8.

Borzabadi-Farahani, A., F. Eslamipour and I. Asgari, 2011. Association between orthodontic treatment need and caries experience. Acta Odontol. Scand., 69: $2-11$.

Creswell, J.W., 2014. Research Design: Qualitative, Quantitative, and Mixed Methods Approaches. 4th Edn., Sage, Thousand Oaks, California, USA., ISBN-13: 978-1452226101, Pages: 273.

Cunnion, D.T., A. Spiro, J.A. Jones, S.E. Rich and C.P. Papageorgiou et al., 2010. Pediatric oral health-related quality of life improvement after treatment of early childhood caries: A prospective multisite study. J. Dent. Children, 77: 4-11.

De Oliveira, K.M.H., M.A. Nemezio, P.C. Romualdo, R.A.B. da Silva, E.S.F. de Paula and E.C. Kuchler, 2017. Dental flossing and proximal caries in the primary dentition: A systematic review. Oral Health Prev. Dent., 15: 427-434.

Ferraz, E.G., E.D.J. Campos, V.A. Sarmento and L.R. Silva, 2012. The oral manifestations of celiac disease: Information for the pediatric dentist. Pediatr. Dent., 34: 485-488.

Hafez, H.S., S.M. Shaarawy, A.A. Al-Sakiti and Y.A. Mostafa, 2012. Dental crowding as a caries risk factor: A systematic review. Am. J. Orthodontics Dentofacial Orthopedics, 142: 443-450.

Hiremath, S.S., 2011. Textbook of Preventive and Community Dentistry. 2nd Edn., RELX India Pvt Ltd., Gurgaon, India, ISBN: 978-81-312-2530-1, Pages: 582.

Hujoel, P.P., M.L.A. Hujoel and G.A. Kotsakis, 2018. Personal oral hygiene and dental caries: A systematic review of randomised controlled trials. Gerodontology, 35: 282-289.

Kraivaphan, P., C. Amornchat, T. Triratana, L.R. Mateo and R. Ellwood et al., 2013. Two-year caries clinical study of the efficacy of novel dentifrices containing $1.5 \%$ arginine, an insoluble calcium compound and 1,450 ppm fluoride. Caries Res., 47: 582-590.

Krishnaswamy, K.N., A.I. Sivakumar and M. Mathirajan, 2016. Management Research Methodlogy: Integration of Principles, Medthods and Techniques. Dorling Kindersley India, Noida, India,.
Laudenbach, J.M. and Z. Simon, 2014. Common dental and periodontal diseases: Evaluation and management. Med. Clin. North Am., 98: 1239-1260.

Listl, S., J. Galloway, P.A. Mossey and W. Marcenes, 2015. Global economic impact of dental diseases. J. Dent. Res., 94: 1355-1361.

Mast, P., M.T. Rodrigueztapia, L. Daeniker and I. Krejci, 2013. Understanding MIH: Definition, epidemiology, differential diagnosis and new treatment guidelines. Eur. J. Paediatr. Dent., 14: 204-208.

Milgrom, P., K.A. Ly, O.K. Tut, L. Mancl, M.C. Roberts, K. Briand and M.J. Gancio, 2009. Xylitol pediatric topical oral syrup to prevent dental caries: A double-blind randomized clinical trial of efficacy. Arc. Pediatrics Adolescent Med., 163: 601-607.

Nikoletseas, M.M., 2014. Statistics: Concepts and Examples. Amazon, Wisconsin, USA., ISBN-13: 9781500815684, Pages: 236.

Otsu, K., M. Kumakami-Sakano, N. Fujiwara, K. Kikuchi, L. Keller, H. Lesot and H. Harada, 2014. Stem cell sources for tooth regeneration: Current status and future prospects. Front. Physiol., Vol. 5, 10.3389/fphys.2014.00036

Petti, S., 2010. Why guidelines for early childhood caries prevention could be ineffective amongst children at high risk. J. Dent., 38: 946-955.

Santos, A.P.P., B.H. Oliveira and P. Nadanovsky, 2013. Effects of low and standard fluoride toothpastes on caries and fluorosis: Systematic review and meta-analysis. Caries Res., 47: 382-390.

Schwendicke, F., C.E. Dorfer, P. Schlattmann, L.F. Page, W.M. Thomson and S. Paris, 2015. Socioeconomic inequality and caries: A systematic review and meta-analysis. J. Dental Res., 94: 10-18.

Sheiham, A. and W.P.T. James, 2014. A new understanding of the relationship between sugars, dental caries and fluoride use: Implications for limits on sugars consumption. Public Health Nutr., 17: 2176-2184.

Silk, H., 2014. Diseases of the mouth. Primary Care Clin. Off. Pract., 41: 75-90.

Silva, M.J., K.J. Scurrah, J.M. Craig, D.J. Manton and N. Kilpatrick, 2016. Etiology of molar incisor hypomineralization-a systematic review. Commun. Dent. Oral Epidemiol., 44: 342-353.

Tellez, M., J. Gomez, I. Pretty, R. Ellwood and A.I. Ismail, 2013. Evidence on existing caries risk assessment systems: Are they predictive of future caries?. Commun. Dent. Oral Epidemiol., 41: 67-78.

Twetman, S. and V. Dhar, 2015. Evidence of effectiveness of current therapies to prevent and treat early childhood caries. Pediatr. Dent., 37: 246-253. 
Twetman, S., 2015. The evidence base for professional and self-care prevention-caries, erosion and sensitivity. BMC. Oral Health, Vol. 15, 10.1186/1472-6831-15-s1-s4

Venturi, S. and M. Venturi, 2009. Iodine in evolution of salivary glands and in oral health. Nutr. Health, 20: 119-134.

Vos, T., A.D. Flaxman, M. Naghavi, R. Lozano and C. Michaud et al., 2012. Years Lived with Disability (YLDs) for 1160 sequelae of 289 diseases and injuries 1990-2010: A systematic analysis for the global burden of disease study 2010. Lancet, 380: 2163-2196.
WHO., 1997. Oral Health Surveys: Basic Methods. 4th Edn., World Health Organization, Geneva, Switzerland,.

WHO., 2009. What is the Burden of Oral Disease?. World Health Organization, Geneva, Switzerland,.

Wackerly, D.D., W. Mendenhall and R.L. Scheaffer, 2008. Mathematical Statistics with Applications. 7th Edn., Thomson Higher Education, Belmont, California, USA., ISBN: 9780495385080, Pages: 612.

Wegner, T., 2008. Applied Business Statistics: Methods and Excel-Based Applications: Solutions Manual. 2nd Edn., Juta \& Co Ltd., Cape Town, South Africa, ISBN: 9780702177354, Pages: 219. 